\title{
Effects of matrix viscosity on morphological and rheological properties and the electrical percolation threshold in graphene/epoxy nanocomposites
}

\author{
A. Alipour ${ }^{*}$, T. Giffney, R. Lin, K. Jayaraman \\ Centre for Advanced Composite Materials, Department of Mechanical Engineering, The University of Auckland, \\ Auckland, New Zealand
}

Received 12 October 2020; accepted in revised form 5 December 2020

\begin{abstract}
Graphene nano-platelets (GNPs) can substantially improve the performance of epoxy resin, but improving effects are highly dependent on GNP dispersion uniformity in the matrix. The aim of the current study is to explore the influence of matrix viscosity on the dispersion of GNPs. Thus, epoxy matrix with three disparate viscosities was reinforced with GNPs varying from 0 to $3 \mathrm{wt} \%$, and the influence of matrix viscosity on dispersion uniformity and thus properties of composites were identified. Significant differences in rheological and electrical percolation thresholds were found with a change in the matrix viscosity. The lowest rheological percolation threshold $(0.3 \mathrm{vol} \%)$ and electrical percolation threshold $(0.53 \mathrm{vol} \%)$ were always observed in specimens based on a low viscosity matrix. X-ray Diffraction (XRD) results also showed that lower viscosity resulted in better GNPs distribution. The visual state of GNPs dispersion with a change in matrix viscosity was also evaluated through Scanning Electron Microscopy (SEM) and optical microscopy. Optical microscopy images confirmed that while the GNP agglomeration diameter is $42.3 \mu \mathrm{m}$ in high-viscosity resin, it markedly decreased to $15.1 \mu \mathrm{m}$ by using low viscosity resin. Transmission Electron Microscopy (TEM) quantitative measurements pertaining to the number of GNP stacked layers also showed that when a low viscosity matrix was used, only 11 layers stack on each other and form thinner clusters compared to 13 and 39 layers in medium and high ones.
\end{abstract}

Keywords: nanocomposites, graphene, matrix viscosity, percolation threshold, dispersion

\section{Introduction}

Epoxy polymers, as one of the highly cross-linked thermoset materials, are extensively used in various applications, including the automotive industry, aerospace, shipbuilding, and electronic devices. However, this kind of material is quite brittle, which consequently restricts applications where high tensile strength and impact resistance are required. Hence, it is of great interest among researchers to enhance the mechanical properties of epoxy, mainly by using fillers. The main challenge is to improve properties without sacrificing other characteristics such as thermo-mechanical performance and modulus. Fillers are generally used to improve the properties of epoxy, but many commonly used fillers are often detrimental to the mechanical and thermal performance of epoxy [1]. Micro fillers can adversely affect the processability of polymers into composites as well as the mechanical properties of the resulting final product [2]. On the other hand, the incorporation of nanoparticles can lead to a significant enhancement in the mechanical and thermal properties of polymers. It has been reported that nanoparticles such as nanoclay [3], nanosilica [4, 5], carbon nanotubes [6, 7], and nanographene $[8,9]$ can substantially enhance the mechanical and functional properties of epoxy. 
Among the aforementioned nanoparticles, GNPs are carbon-based nanofillers with a two-dimensional structure, having a higher surface area in comparison with any other material of this kind, which results in substantial interactions when incorporated into the polymer matrix. Several researchers have reported the superior performance of GNPs in enhancing the mechanical and thermal properties of epoxy composites in comparison to other carbon-based fillers such as carbon black and carbon nanotubes [8, 10-11]. Nonetheless, before exploiting GNPs, there are some challenging issues with their processing that need to be overcome. Foremost, the strong van der Waals forces between the sheets of as-received graphene contribute to the formation of severe agglomerations once incorporated into the polymer matrix [13] that will decrease the efficiency of load transfer from the matrix to the sheet [14]. It is hypothesized that optimum electrical and mechanical properties will only be achieved when the graphene particles are fully dispersed (achieving separately layered graphene in the final composite). It should also be considered that the uniform dispersion of GNPs throughout the polymer matrix is dependent not only on processing conditions and functional groups in the polymer chain and GNPs surfaces but also on the characteristics of the polymer itself. Thus, it can be deduced that applying a proper processing method, creating functional groups on the surfaces of nanosheets as well as examining polymer pivotal characteristics all help to achieve GNP uniform dispersion in the final nanocomposites. These factors do play paramount roles in determining the improvement rate in macroscopic properties of the resulting nanocomposites. Of all factors, the first and second ones have been extensively investigated and reported in the literature [2, 12-15].

In addition to the first and second factors, some studies have investigated the effects of polymer matrix physical characteristics, such as viscosity, in the field of polymer nanocomposites. Dong and Bhattacharyya [16] examined the dispersion of nanoclay in polypropylene (PP) with different viscosities. They found that PP viscosity played the most significant role in nanoparticle dispersion and consequently in properties improvement. Indeed, the uniform dispersion of organoclay sheets more easily achieved in the PP with a lower viscosity resulted in better mechanical performance. Ha et al. [17] also observed that the dispersion of multiwalled carbon nanotubes (MWCNTs) in both polycarbonate (PC) and PP became less uniform as matrix viscosity increased. Their findings showed that a high viscosity matrix significantly restricted the mobility of nanoparticles, which consequently hindered them from separating from each other and eventually leading to the formation of clusters. Hermant et al. [18] also showed that upon using low viscosity polystyrene and poly (methylmethacrylate) as polymer matrices in CNTs reinforced composites, the percolation threshold of electrical conductivity shifted to lower values, which is an indication of uniformly dispersed nanoparticles.

In order to gain quantitative insight into the dispersion of nanofillers in a polymer matrix, indirect measurements based on dynamic rheological analysis and electrical conductivity can be used efficiently [1924]. This is mainly due to the fact that the dispersion quality of nanoparticles is greatly correlated with rheological and electrical properties. In addition, because of significant distinctions between the physical characteristics of GNPs and a polymer matrix, incorporation of GNPs can bring about substantial enhancements in physical, particularly in rheological and electrical properties of a polymer, when GNP percentage exceeds a specific point. The dramatic changes in the physical characteristics of polymeric nanocomposites can be evaluated by percolation theory because the particles of dispersed phase commence forming a continuous network in the matrix at a specific volume fraction known as the percolation threshold, which is governed by different factors, including the level of GNP dispersion [25], GNPs/matrix interaction [26] and matrix viscosity [27]. Thus, the influence of these factors can be examined through percolation threshold theory to observe how they affect the quality of the final nanocomposite.

Additionally, many other studies have investigated the effect of either graphene modification or different processing methods on GNP dispersion, and subsequently, the properties of GNPs reinforced epoxy matrix. Nevertheless, to the best of the author's knowledge, no study has been conducted on examining the effect of various viscosities on GNP dispersion in epoxy. The intention of this work was to establish a correlation between the viscosity of the matrix with GNP distribution. Therefore, GNPs of different contents were incorporated into the epoxy matrix of three disparate viscosities, and the status of dispersion was evaluated with various techniques. 
The change in GNP dispersion with viscosity alteration was evaluated with the percolation threshold of rheological and electrical properties. Morphological techniques such as XRD, TEM, SEM, and optical microscopy were also employed to provide a far more clear view of how GNP dispersion status alters in epoxy with different viscosities.

\section{Materials and procedures}

\subsection{Materials}

Three different Diglycidyl ether of bisphenol A (DGEBA) epoxy resins (the molecular weight of $340 \mathrm{~g} / \mathrm{mole}$ ), including 105 West System, ADR 230, and ADH 230, with polyamine curing agents (molecular weight of $103.17 \mathrm{~g} / \mathrm{mole}$ ) were supplied by Adhesive Technologies Ltd. in New Zealand. The required amount of hardener for the curing process was considered according to the manufacturer's data sheet and calculated based on the molecular weight of amine, the number of available hydrogens per molecule, and epoxy equivalent weight. The typical chemical structures of epoxy resin and polyamine hardener are shown in Figure 1. Commercial graphene nano-platelets (GNPs) with an average thickness of $5 \mathrm{~nm}$, width of $5 \mu \mathrm{m}$ and density of $2.2 \mathrm{~g} / \mathrm{cm}^{3}$ were supplied by EMFUTUR, Spain. Table 1 shows the details of the epoxies used in this study.

\subsection{Sample preparation}

Initially, the designated amount of GNPs $(0,0.5,1$, $1.5,2,2.5 \& 3 \mathrm{wt} \%$ of the resulting nanocomposites) was weighed and mixed with ethanol $(100 \mathrm{ml} / 0.1 \mathrm{gr}$ GNPs) in a magnetic stirrer for 45 minutes. Then, epoxy was added, and the achieved solution was

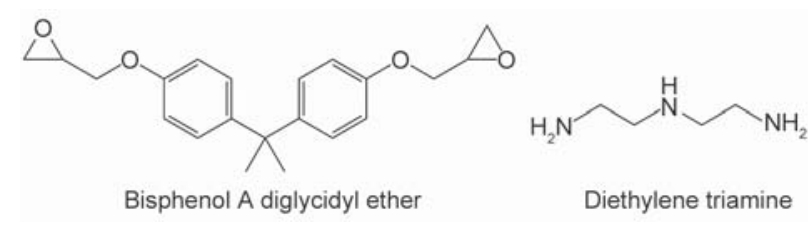

Figure 1. Typical chemical structure of epoxy and hardener used in this study. mixed by a shear mixer at the rotor speed of $2000 \mathrm{rpm}$ for 90 minutes. It should be mentioned that ethanol was not soluble in epoxy. The mixture of epoxy and GNPs (without hardener) was subsequently heated at the temperature of $80^{\circ} \mathrm{C}$ under shear mixing with a low rotor speed (200 rpm) for 8 hours to remove the residual ethanol and was cooled down to room temperature. Next, it was degassed in the vacuum chamber at $21^{\circ} \mathrm{C}$ to remove the bubbles following the addition of the hardener and manual stirring for 1-2 minutes with a resin-to-hardener weight ratio provided by the manufacturer. The solution was then poured into a silicon rubber mold and cured on the basis of datasheets. The cured samples were used for different analyses, including XRD, TEM, SEM, and electrical conductivity.

\subsection{Characterisation}

X-ray diffraction (XRD) analysis of composite samples was carried out with a D2 Phaser Bruker Diffractometer (USA) by using a $\mathrm{Cu} \mathrm{K} \alpha$ radiation source at the wavelength of $\lambda=1.5406 \AA$, a voltage of $45 \mathrm{kV}$ and electric current of $300 \mathrm{~mA}$. The range of $2 \theta$ scanning was from 10 to $60^{\circ}$ and with the scanning rate of $5 \% \mathrm{~min}$. The dispersion status of uncured GNP reinforced epoxy was viewed using an optical microscope (LEICA DM 2500, USA) under a bright field. In addition, for ultramicrotomy, the resin strip was cut down to a $10 \mathrm{~mm} \times 3 \mathrm{~mm}$ block, and one end was trimmed to a $1 \mathrm{~mm} \times 1 \mathrm{~mm}$ face. A Leica EM UC6 ultramicrotome (Leica Microsystems, USA) equipped with a 45 degree diamond knife (Diatome) was used to cut $100 \mathrm{~nm}$ sections that were collected onto 200 mesh copper specimen grids. Then, to observe the GNP networks in the epoxy matrix, the samples were viewed using a Philips TEM. The morphology of samples was analyzed using a scanning electron microscope (SEM, FEI Quanta 200F, USA). The samples were coated with platinum before SEM analysis. DC electrical measurements were performed using a Keithley 220 electrometer, UK. Rheological

Table 1. Details of epoxy used in this study.

\begin{tabular}{|c|c|c|c|c|}
\hline Epoxy type & $\begin{array}{c}\text { Epoxy } \\
\text { nomenclature }\end{array}$ & $\begin{array}{c}\text { Viscosity } \\
\text { [cps] }\end{array}$ & Hardener & $\begin{array}{c}\text { Hardener ratios } \\
\text { [parts per hundred resin] }\end{array}$ \\
\hline $\begin{array}{c}105 \text { West System } \\
\text { (Low Viscosity Resin) }\end{array}$ & LVR & 430 & Extra slow hardener 209 & 11.4 \\
\hline $\begin{array}{c}\text { ADR 230 } \\
\text { (Medium Viscosity Resin) }\end{array}$ & MVR & 1160 & ADH 230 & 10.6 \\
\hline $\begin{array}{c}\text { ADR 240 } \\
\text { (High Viscosity Resin) }\end{array}$ & HVR & 2830 & ADH 240 \\
\hline
\end{tabular}


properties of uncured resin were measured using a Physica UDS 200 (Austria) that has the parallel plate geometry with an oscillation frequency growing from 0.1 to $100 \mathrm{rad} / \mathrm{s}$, at room temperature and strain of $1 \%$. Dynamic mechanical properties of epoxy composites were recorded using a DMA Q800 (USA) in the tensile mode at the frequency of $1 \mathrm{~Hz}$, a dynamic strain of $0.1 \%$ in the temperature ranging from $20^{\circ} \mathrm{C}$ to $200^{\circ} \mathrm{C}$ and the heating rate of $3^{\circ} \mathrm{C} / \mathrm{min}$.

\section{Results and discussion}

\subsection{Morphology and microstructure of GNP reinforced epoxy}

\subsubsection{X-ray diffraction}

Figure 2 demonstrates XRD patterns of epoxy with different viscosities reinforced with $1 \mathrm{wt} \%$ of GNPs. This analysis was conducted to examine the degree of GNP intercalation in different matrix viscosities. As seen, a wide diffraction pattern from 10 to $30^{\circ}$ with a peak at $18^{\circ}$ appears in XRD patterns, which results from the scattering of cured epoxy molecules, indicating its amorphous nature [28]. Furthermore, the peak that appeared at $26.4^{\circ}$ is related to the $(002)$ graphitic plane of GNPs [29]. More importantly, there is a distinct difference between the intensities of studied composites despite the fact that all contain the same amount of GNPs. Generally, widening or any alteration in intensity is regarded as an indication of intercalation or exfoliation [30]. The decline in peak intensity or broadening of peaks in XRD patterns indicates that nanoparticles have better distribution and become more intercalated $[31,32]$. As observed, the intensity of graphitic peaks in the X-ray patterns of the sample made from LVR declines significantly, implying that GNPs have better distribution in this specimen and become more intercalated. Indeed, the decline of $(002)$ peak intensity at $2 \theta=26.4^{\circ}$ for the specimen based on LVR indicates that the thickness of GNPs is reduced, and nanosheets with quite a few numbers of graphitic layers have formed. Subsequently, the intensity of graphitic peak for the composites based on MVR is higher than that with LVR exemplifying the retention of thicker graphene layers. The composite specimen manufactured with HVR has the highest peak indicating the formation of more agglomerations in comparison with those based on MVR and LVR. It should also be mentioned that a complete exfoliation has not been achieved in any composite samples since the original graphitic peak did not disappear.

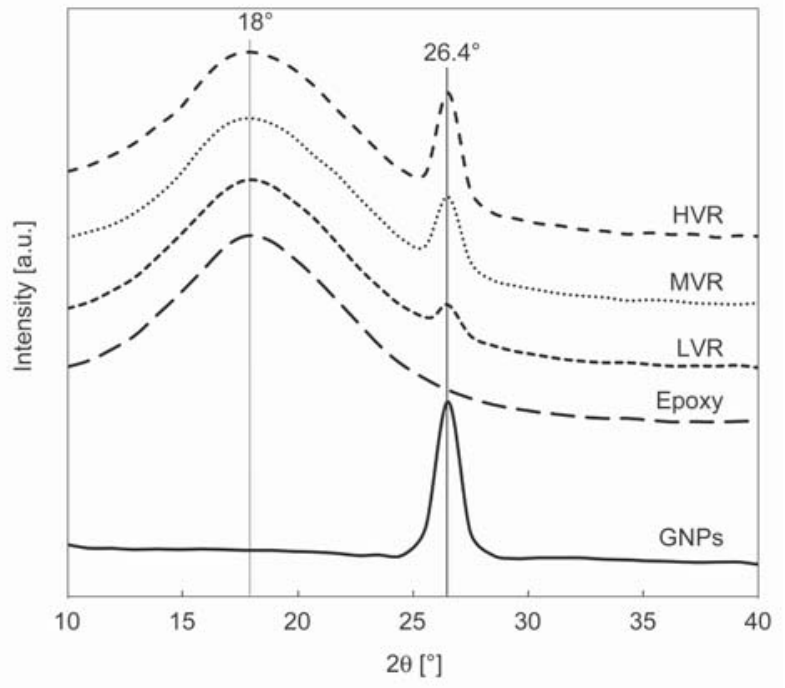

Figure 2. XRD patterns of epoxy with different viscosities reinforced with $1 \mathrm{wt} \%$ of GNPs.

\subsubsection{Scanning electron microscopy (SEM)}

The morphology of pure epoxy and its composites reinforced with $1 \mathrm{wt} \%$ of GNPs were examined through SEM and depicted in Figure 3. As seen, while plain epoxy shows a river-like surface, the incorporation of GNPs makes the smooth surface of epoxy much bumpy, which is an indication of interaction between nanosheets and polymer chains. More importantly, GNPs have distinctively located in composite manufactured with different viscosities. In composite made from LVR, GNPs are sparsely located, no severe agglomeration is observed, and nanosheets are homogenously dispersed (see the selected parts and blown-out images). On the other hand, the GNPs agglomerations become visible, and more sheets stack to each other when matrix viscosity increases. In HVR, the poorly dispersed GNPs can vividly be observed, which indicates that the status of nanosheets dispersion in the polymer matrix is not uniform, and they hardly separate from each other. It is worth noting that poorly dispersed GNPs in the epoxy matrix will act as stress concentration leading to a localized weakness and thus reducing properties of composites.

\subsubsection{Transmission electron microscopy (TEM)}

Figure 4 also summarises the TEM morphological observation of epoxy composites with three different viscosities reinforced with $1 \mathrm{wt} \%$ of GNPs. From these images, it is clearly observable that with an increase in matrix viscosity, more nanosheets stack to each other, and consequently, separating layers becomes much more challenging. In samples made 


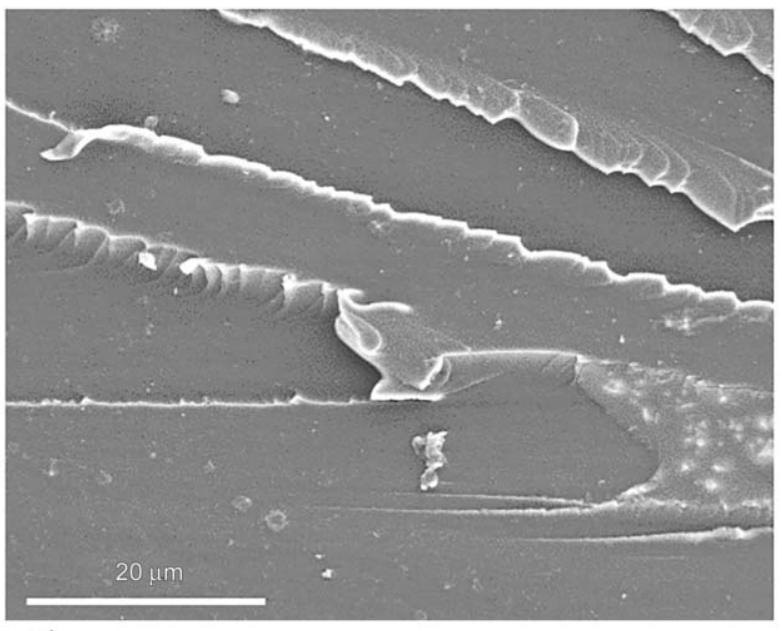

a)

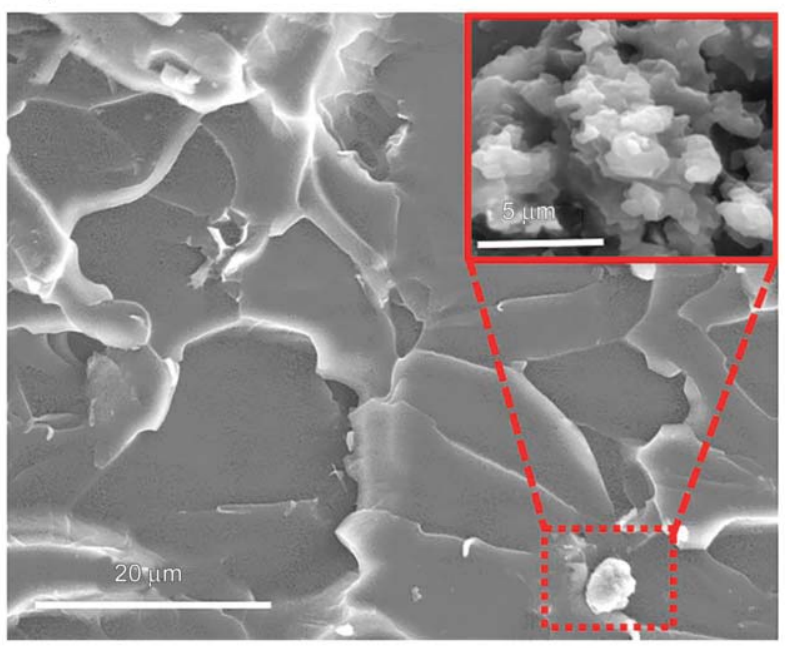

c)

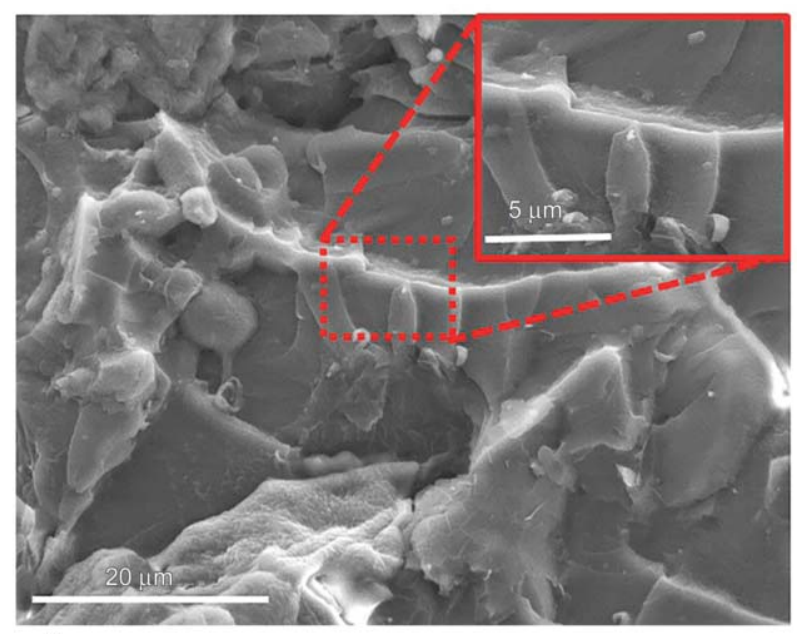

b)

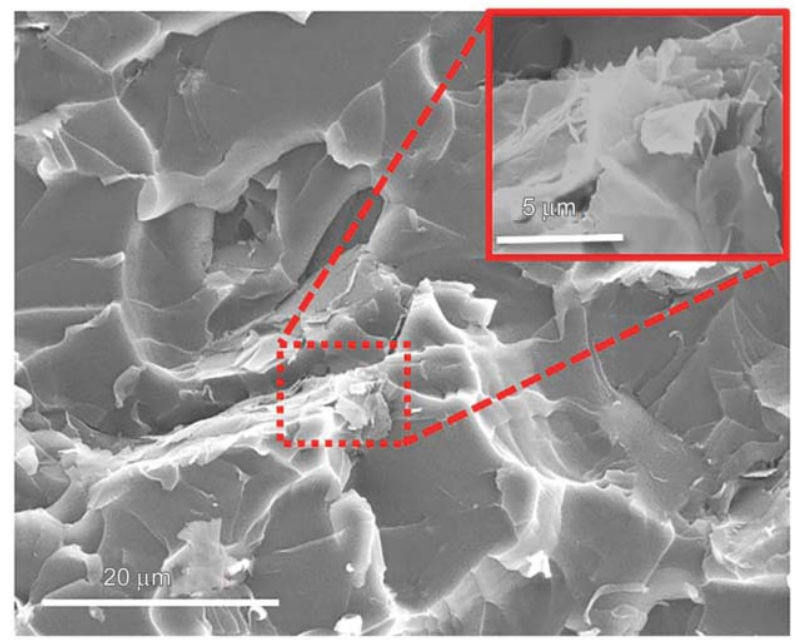

d)

Figure 3. SEM image of a) plain epoxy, and epoxy composites reinforced with $1 \mathrm{wt} \%$ of GNPs based on b) LVR, c) MVR and d) HVR.

from LVR, folded and quite separated GNPs are seen while thicker clusters of nanosheets have formed in one made from MVR. In HVR, much thicker nanosheets (darker areas) can be observed, which exemplify forming severe agglomerations in these composites. Additionally, the magnified TEM images also demonstrate the most common thickness of GNPs observed in the samples. Considering the fact that graphite interlayer distance is $0.335 \mathrm{~nm}$, the number of dispersed GNPs in the epoxy matrix with different viscosities can be quantified. In the case of LVR, the thickness is $3.7 \mathrm{~nm}$, which means the dispersed GNPs encompass about 11 graphene layers. In MVR, the common thickness is $6.2 \mathrm{~nm}$ indicating nearly 19 stacked layers, and finally, HVR with the thickness of $13.1 \mathrm{~nm}$ had about 39 layers. Thus, the TEM findings also confirm that using more viscous resin results in bigger agglomerations, which is in accordance with SEM results. In XRD results shown in Figure 2, a significant divergence between the intensities of composites based on LVR, MVR, and HVR at $2 \theta=$ $26.4^{\circ}$ was observed. The lowest peak intensity pertained to composites based on LVR thanks to the reduction in platelet thickness that also was substantiated in TEM findings.

\subsubsection{Dispersion level of GNPs in epoxy nanocomposites}

In order to investigate the effect of matrix viscosity on GNP distribution uniformity, the uncured GNP/ epoxy samples were viewed using transmission optical microscopy. Figure 5 presents microscopic images taken from composites at $1 \mathrm{wt} \%$ graphene made from different matrix viscosities. At a fixed GNP loading, the dispersion level of nanosheets in epoxy matrix alters and agglomerations become more apparent when matrix viscosity increases. In LVR based composites, the particles have better distribution, and few agglomerations can be observed, demonstrating that the dispersion of GNPs in this matrix is 


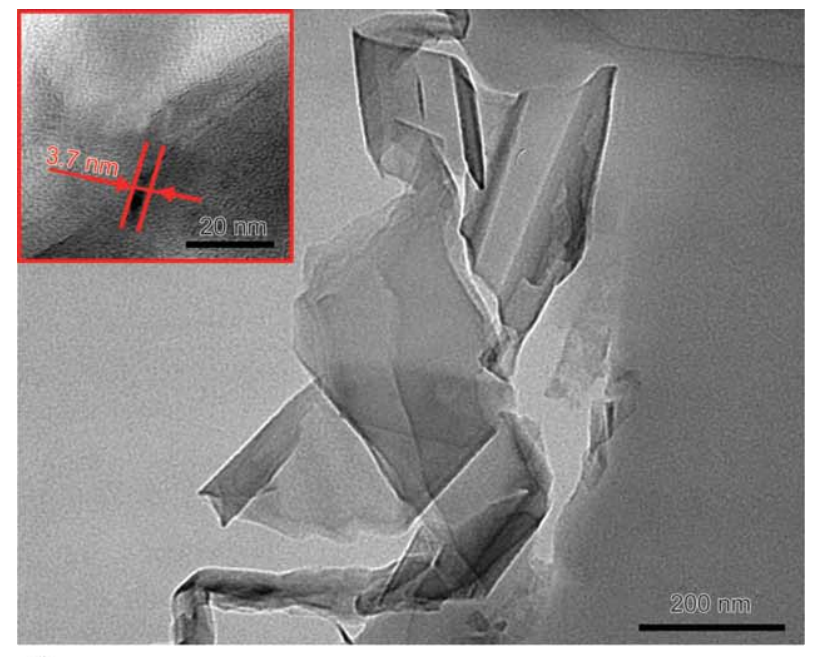

a)

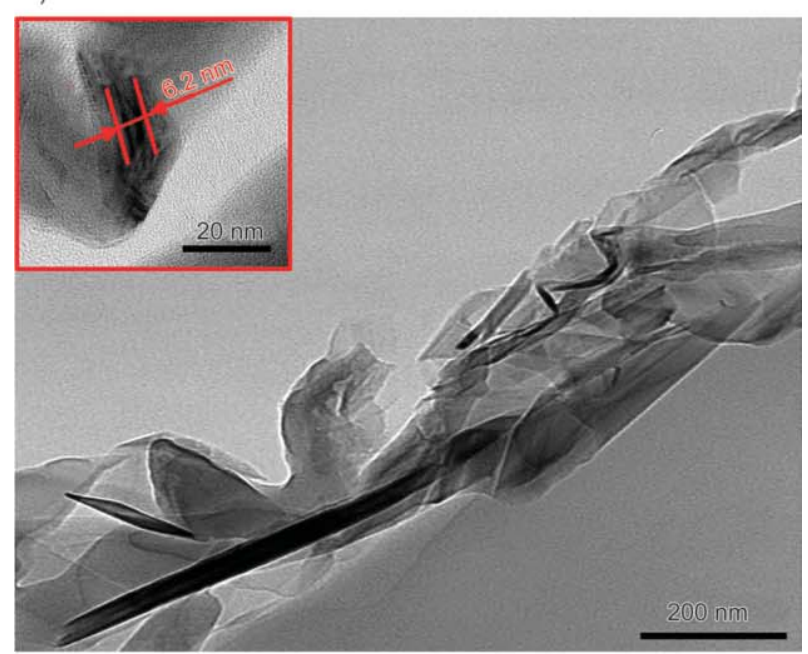

b)

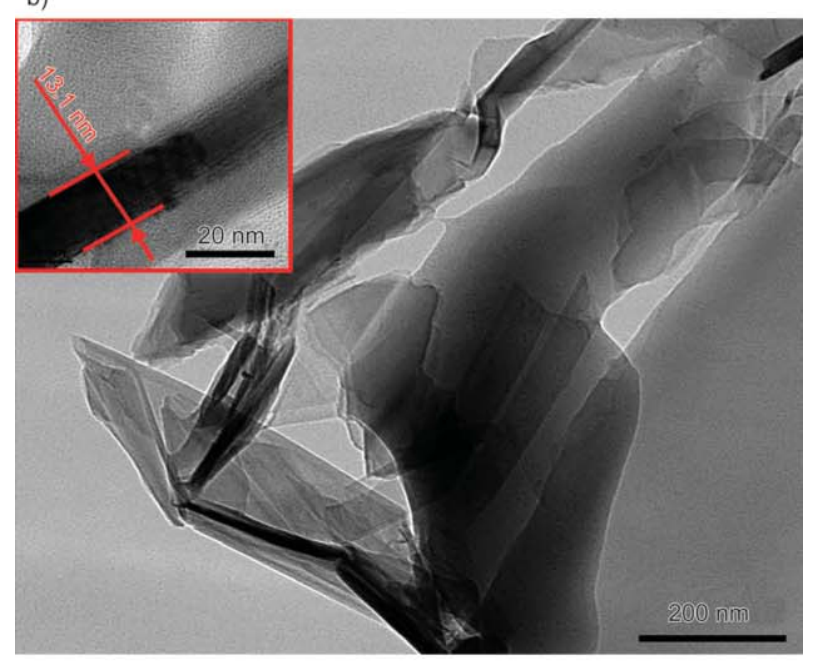

c)

Figure 4. TEM image of a) LVR b) MVR and c) HVR nanocomposites containing $1 \mathrm{wt} \%$ of GNPs.

much better than in MVR and HVR ones. The formation of thicker agglomerations is very clear for higher viscosities due to the difficulty of GNP dispersion. In HVR, polymer chains confine GNPs, and consequently, they hardly separate from each other.

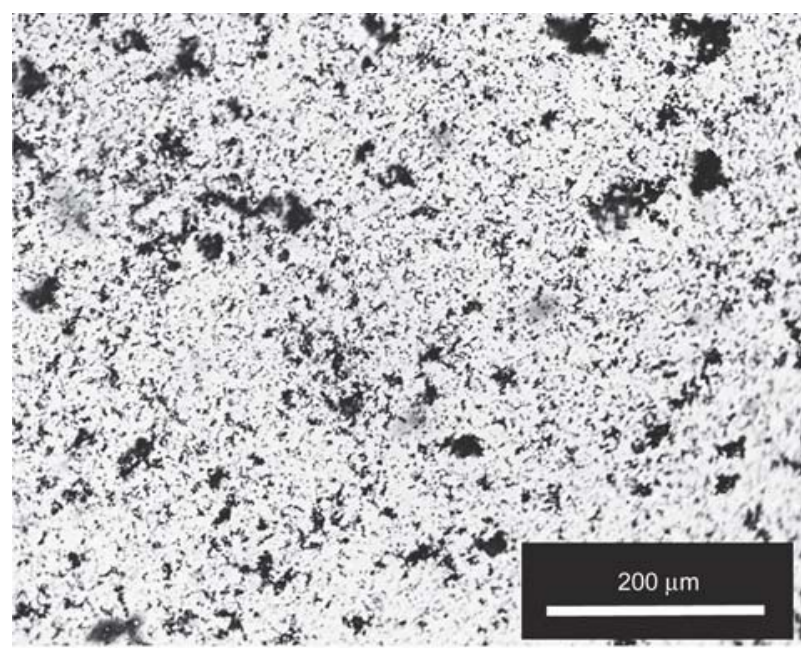

a)

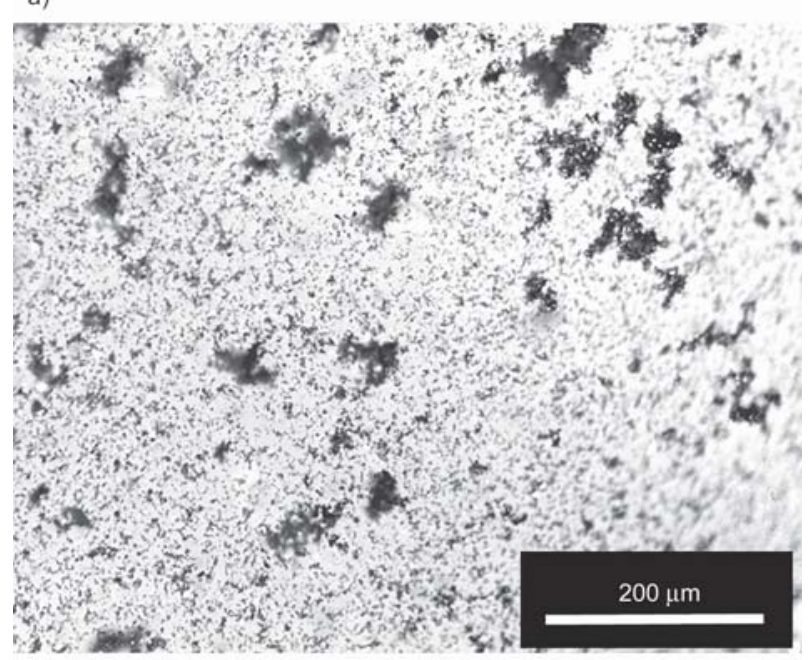

b)

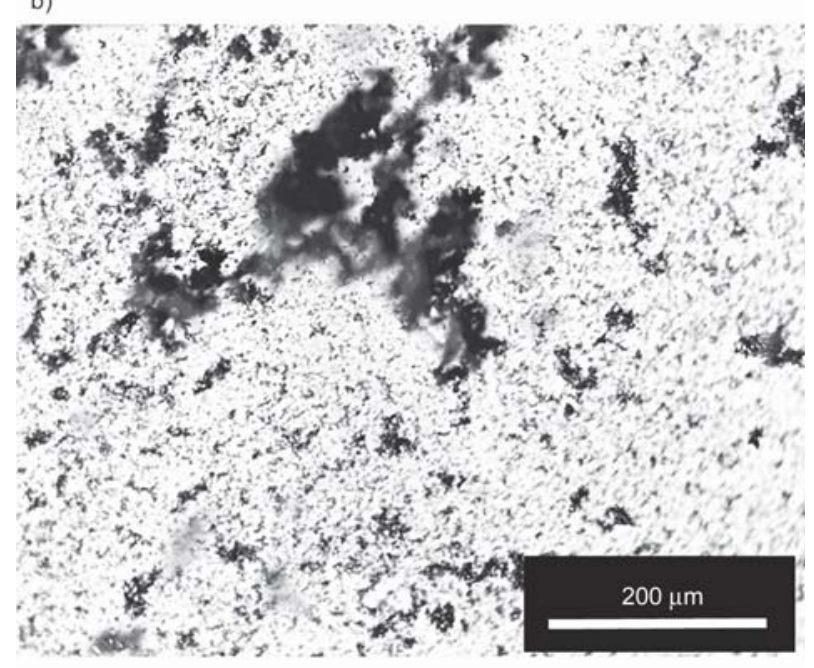

c)

Figure 5. Dispersion of 1 wt $\%$ of GNPs in a) LVR b) MVR and c) HVR.

Thus, it could be deduced that for dispersing graphene sheets, the resin viscosity does play a pivotal role in reducing agglomerations and achieving a more uniform distribution. Additionally, as Figure 6 shows, an increase in graphene loading contributes to the 


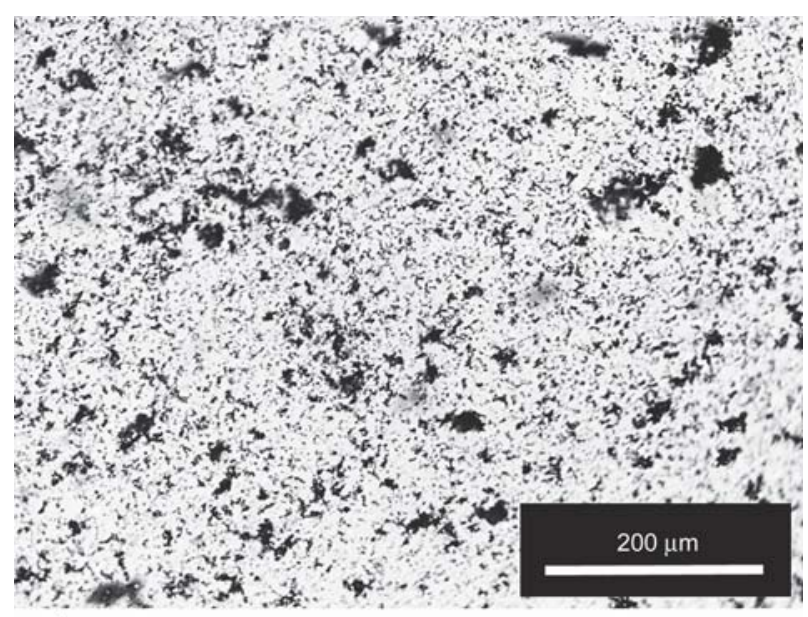

a)

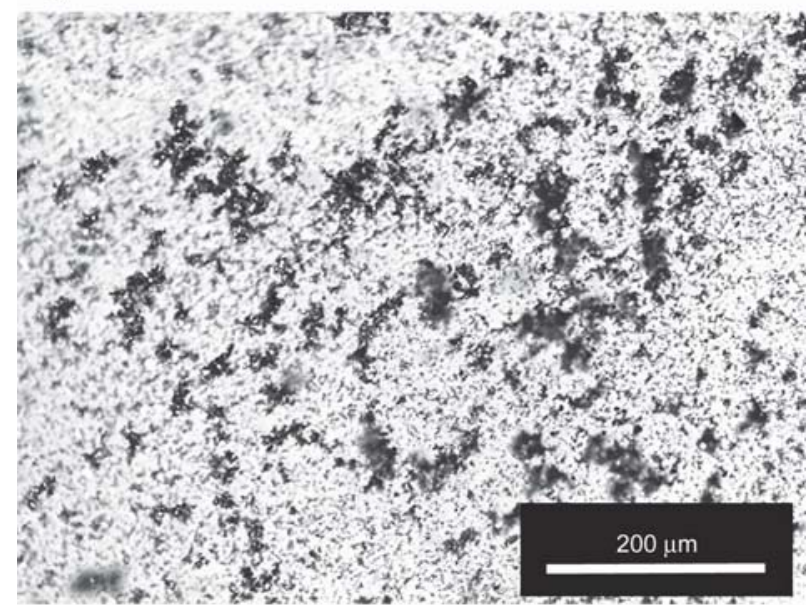

b)

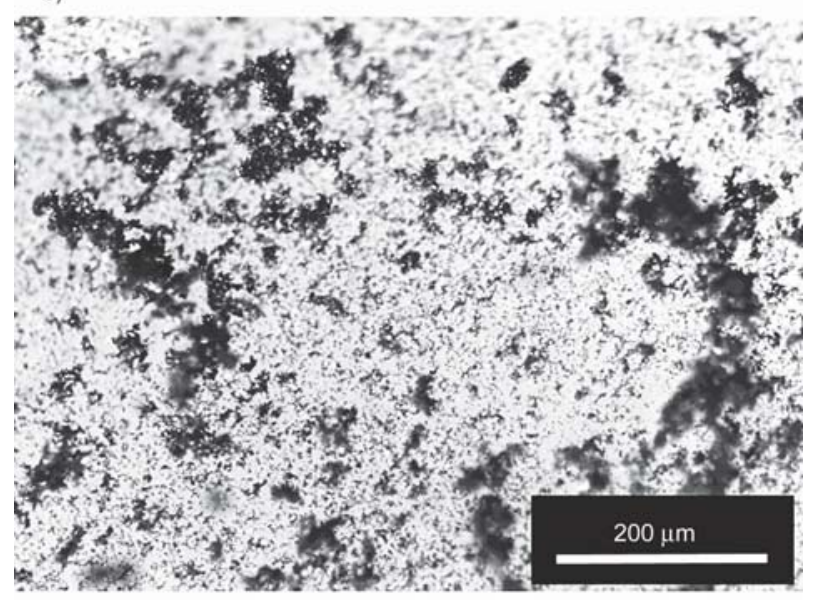

c)

Figure 6. Dispersion of a) $1 \mathrm{wt} \%$ b) $1.5 \mathrm{wt} \%$ and c) $2 \mathrm{wt} \%$ of GNPs in LVR.

formation of more pronounced GNP clusters because, at higher contents, the separation of nanosheets becomes more challenging.

To investigate the effect of matrix viscosity on GNP dispersion more precisely, the size (the surrounding circle around each cluster) of 150 GNP agglomerations out of the total number of agglomerations

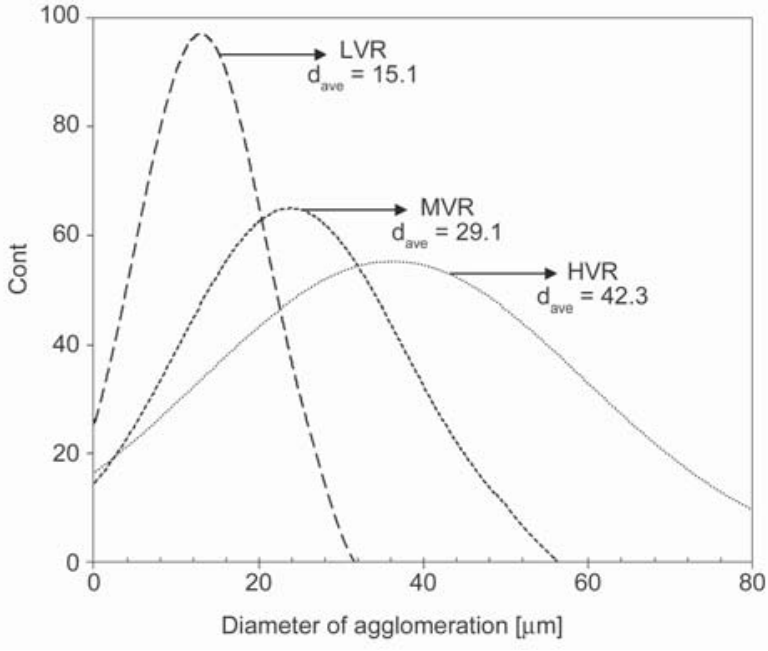

Figure 7. Size distribution of GNPs in epoxy with different viscosities.

pictured in each composite sample was measured using Image Analyser software. The results of this analysis are shown in Figure 7. As observed, the average agglomeration diameter (dave) is markedly dependent on matrix viscosity. The value of $d_{\text {ave }}$ reduces as matrix viscosity shifts to lower values. The agglomeration size distribution for HVR based composite is broad, and with a reduction in matrix viscosity, it becomes narrower and also $d_{\text {ave }}$ shifts to lower values (from 42.3 to $15.1 \mu \mathrm{m}$ ). This also parallels XRD, SEM, and TEM findings substantiating the better dispersion of GNPs in LVR.

\subsection{Rheological properties}

Rheological properties are useful indications for realizing the dispersion level of nanoparticles in the polymer matrix [21,32]. Because the state of particle dispersion and interactions between polymer/nanoparticles are closely integrated with rheological properties, this measurement provides another indication to examine nanoparticles distribution throughout the epoxy matrix. The higher storage modulus indicates a better interaction of matrix with graphene sheets, which is hypothesized to be the result of more uniform distribution of sheets and their entanglements with polymer chains. Therefore, the effect of different epoxy viscosities on GNP dispersion was investigated through rheological measurements. As seen in Figure 8, the storage modulus of pure epoxy resin shows a linear viscoelastic response like a liquid. Besides, the storage modulus significantly increases once GNPs are incorporated, and then it reaches a stable plateau demonstrating non-terminal or solidlike flow behavior. But, there is a distinct difference 

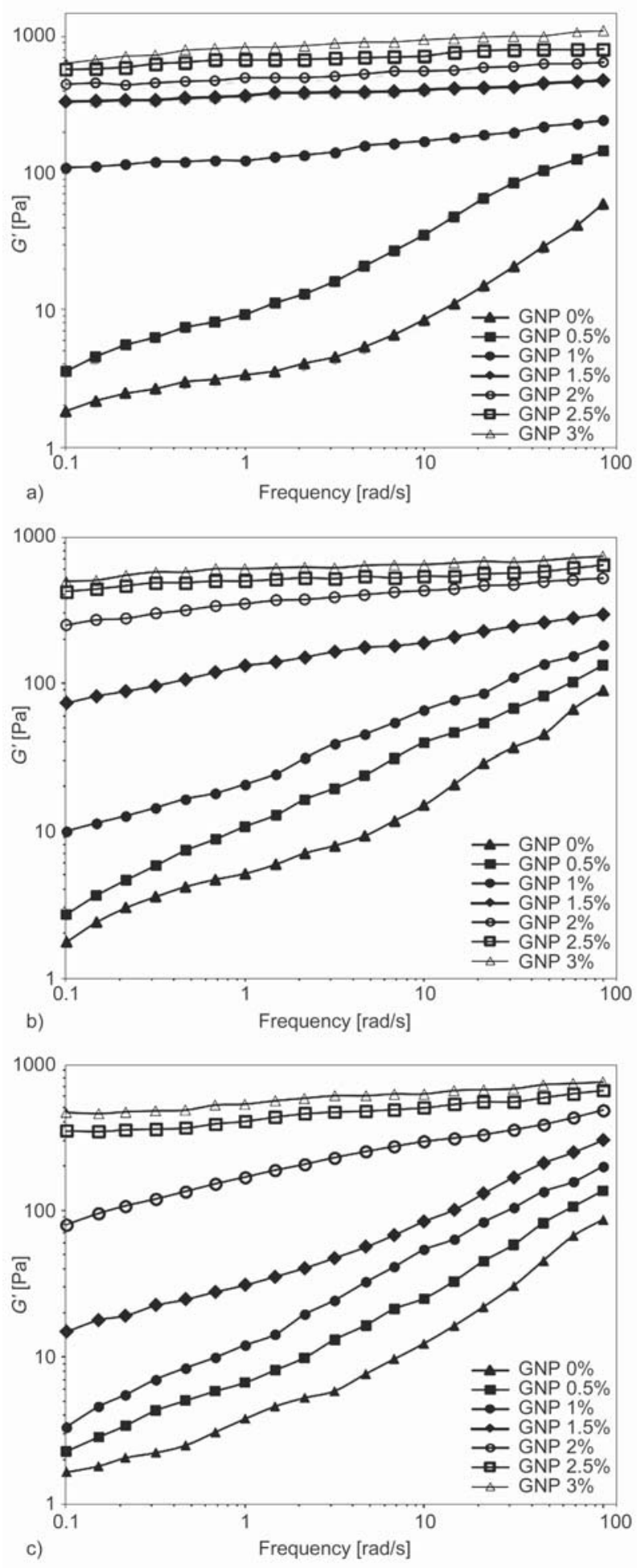

Figure 8. Storage modulus as a function of frequency for nanocomposites made from a) LVR, b) MVR and c) HVR reinforced with different contents [wt $\%]$ of GNPs.

in GNPs concentration in which the storage modulus of composites nearly levels off. This phenomenon happens at higher concentrations of GNPs as matrix viscosity increases. Indeed, these results indicate the formation of GNPs networks in the epoxy matrix in lower concentrations when LVR is used. Furthermore, at a fixed graphene loading, samples manufactured with LVR possess a higher value of storage modulus. When nanosheets are added to epoxy, an interconnected network of particles is formed. The stronger network, mainly originating from a more uniform dispersion, results in further enhancement of storage modulus [33-35]. As seen, LVR-based composites show higher storage modulus, which is an indication of the formation of a stronger, interconnected network of GNPs thanks to a more uniform GNP dispersion.

In rheological measurements, the moduli at low-frequency values can demonstrate some information about the status of GNPs dispersion [19]. The storage modulus of composites receives a significant increase by GNP incorporation, especially at low frequencies, which is an indication of non-terminal or solid-like behavior [19]. As mentioned, the storage modulus in all composite specimens shows an upward trend, then reaches a plateau and becomes more independent of angular frequency as the amount of GNPs incorporated increases. Because storage modulus values are sensitive to percolation of GNP networks, the data of $G^{\prime}$ at a frequency of $0.1 \mathrm{rad} / \mathrm{sec}$ was fitted with a power-law (Equation (1)) to determine the percolation threshold of storage modulus in the studied composites made from of matrices with different viscosities:

$X \alpha\left(\phi-\phi_{c}\right)^{b}$

where $X$ represents storage modulus, $\phi$ is the volume fraction of GNPs, $\phi_{\mathrm{c}}$ is the critical volume fraction at the percolation threshold, and ' $b$ ' is the critical scaling exponent used to determine the mechanism of GNPs network formation [36]. The visual conception of the percolation threshold can be found in the literature [37]. The rheological percolation threshold of composites was determined from Figure 9, and the contour plots are shown in Figure 10. Contour plots represent the relationship among three numeric variables in two or three dimensions. The areas with the same color indicate a constant value of the responding variable. Not surprisingly, the percolation threshold for composites made from LVR is lower $\left(\phi_{\mathrm{c}}=0.3 \mathrm{vol} \%\right)$ in comparison with MVR $\left(\phi_{\mathrm{c}}=\right.$ 0.6 vol $\%)$ and HVR $\left(\phi_{\mathrm{c}}=0.8 \mathrm{vol} \%\right)$, because the percolation threshold of rheological parameters all is influenced by the formation of GNP networks 


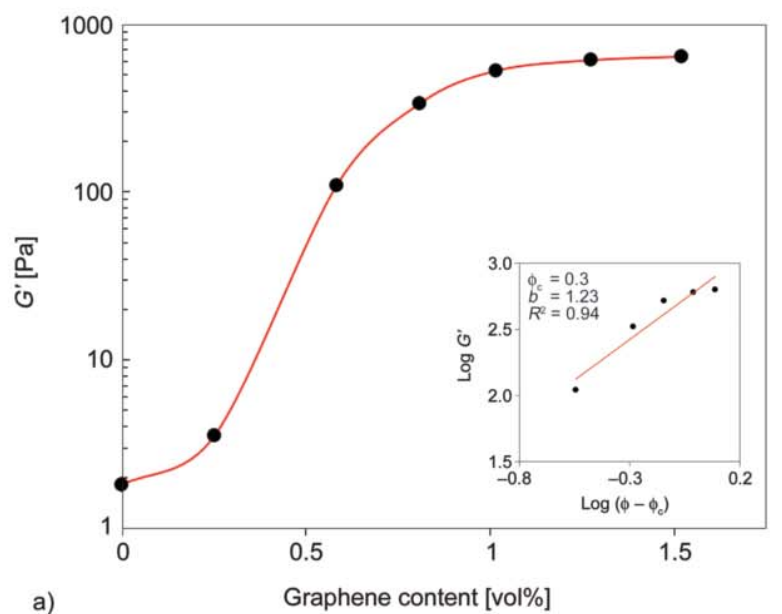

a)
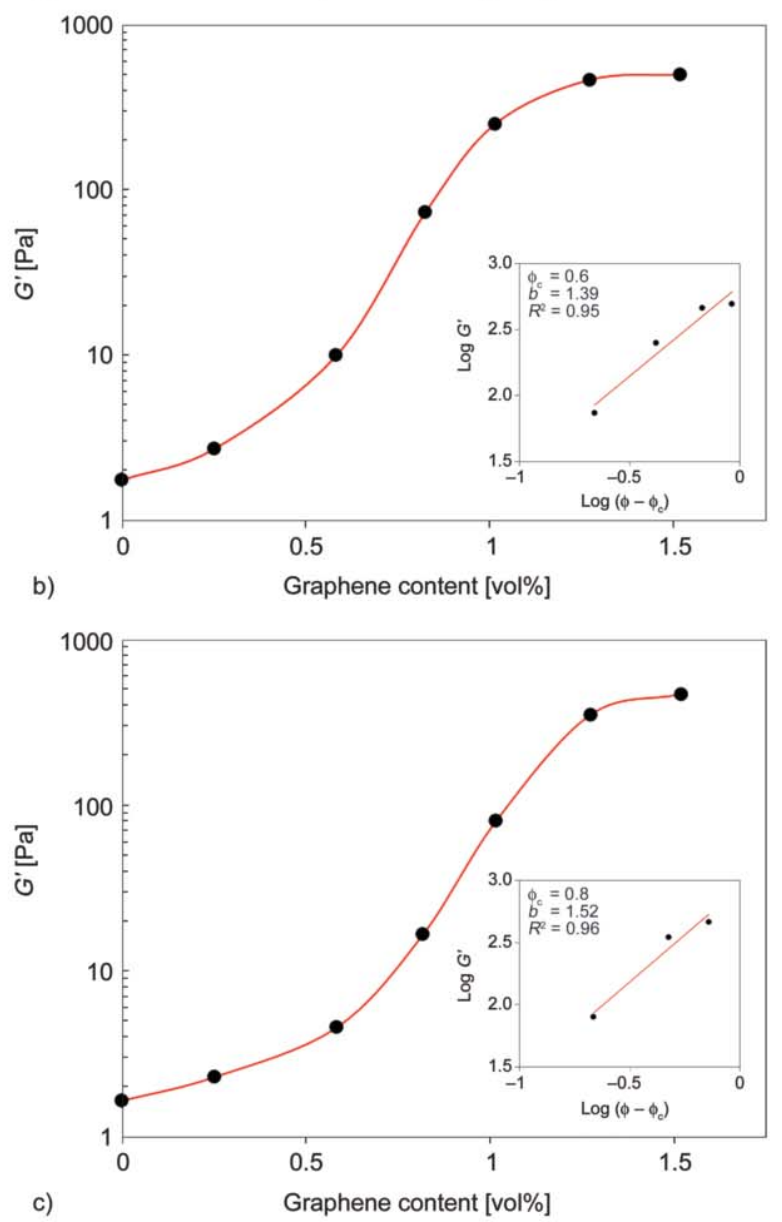

Figure 9. Storage modulus of epoxy nanocomposites, at frequency of $0.1 \mathrm{rad} / \mathrm{s}$, as a function of GNPs loading for a) LVR, b) MVR and c) HVR. Inset demonstrated $\log -\log$ plots of $G^{\prime}$ against $\left(\phi-\phi_{c}\right)$.

[19]. In other words, the lower percolation threshold is attributed to the uniform dispersion of GNPs in the composites [19], which is in agreement with the previously discussed results.

Likewise, in the double logarithmic graphs of $G^{\prime}$ versus $\phi-\phi_{\mathrm{c}}$ and the fitted line along with $b$ values prove that dispersion of GNPs plays a pivotal role in $b$ values. Indeed, $b$ value is inversely proportional to

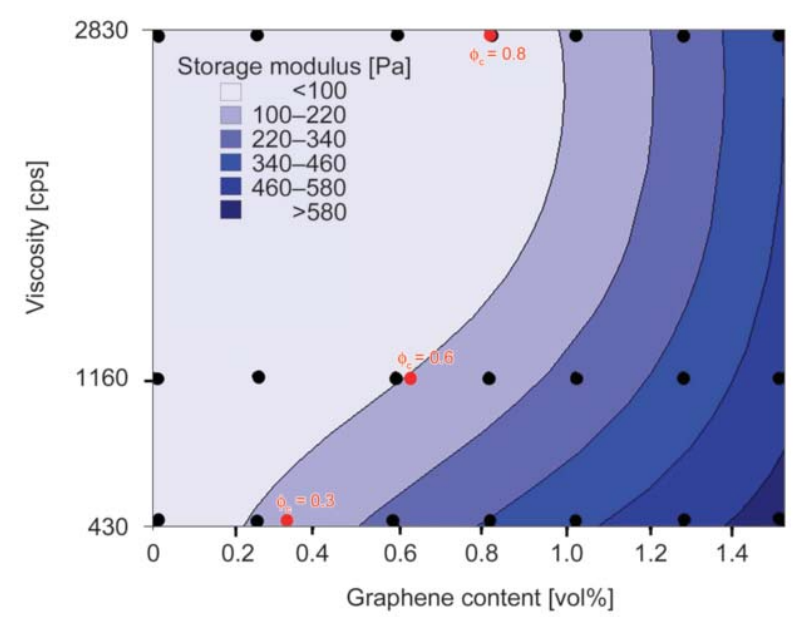

Figure 10. Contour plot showing the role of GNP content and viscosity variation in storage modulus of composites at a frequency of $0.1 \mathrm{rad} / \mathrm{s}$.

GNPs agglomeration [38], which is in agreement with results quantified in TEM. The adjusted correlation coefficient, $R^{2}$, also shows the acceptability of fitted values.

\subsection{Electrical conductivity}

The changes in electrical conductivity of composites with GNPs addition were determined and depicted in Figure 11. It is quite evident that electrical conductivity is highly dependent on GNPs content. As seen, GNPs could be considered as a useful filler in enhancing the electrical conductivity of epoxy resin. All epoxies showed an upward trend and became more conductive by the incorporation of GNPs. At the same time, the samples based on LVR depicted more enhancement in conductivity in comparison with others. This phenomenon is attributed to the better GNPs dispersion in the LVR, since a more uniform dispersion effectively increases the formation of a conductive network [39]. It has been widely accepted that individual sheets of GNP can be linked to wrinkled sheets and consequently heighten the electrical conductivity. According to Alig et al. [40], the conductive network consists of myriads few-layered graphene sheets, and thin stacks of sheets bridged by crumpled GNPs. Hence, this network is regarded as a network composed of GNPs which are separated by regions while polymer chains exist inbetween [40].

In addition, at a specific volume content of GNPs, the electrical conductivity of composites rose rapidly and from that point onward remained nearly unchanged. The volume fraction of GNPs in which electrical conductivity demonstrates a substantial upward 


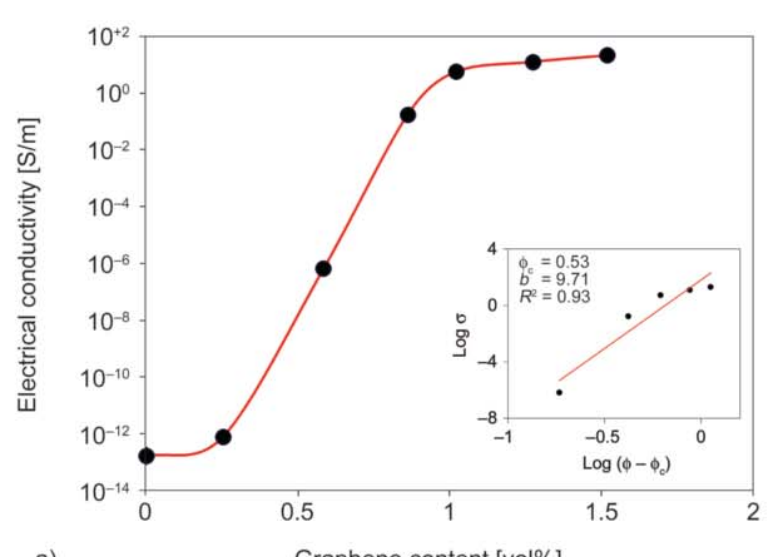

a) Graphene content [vol\%]
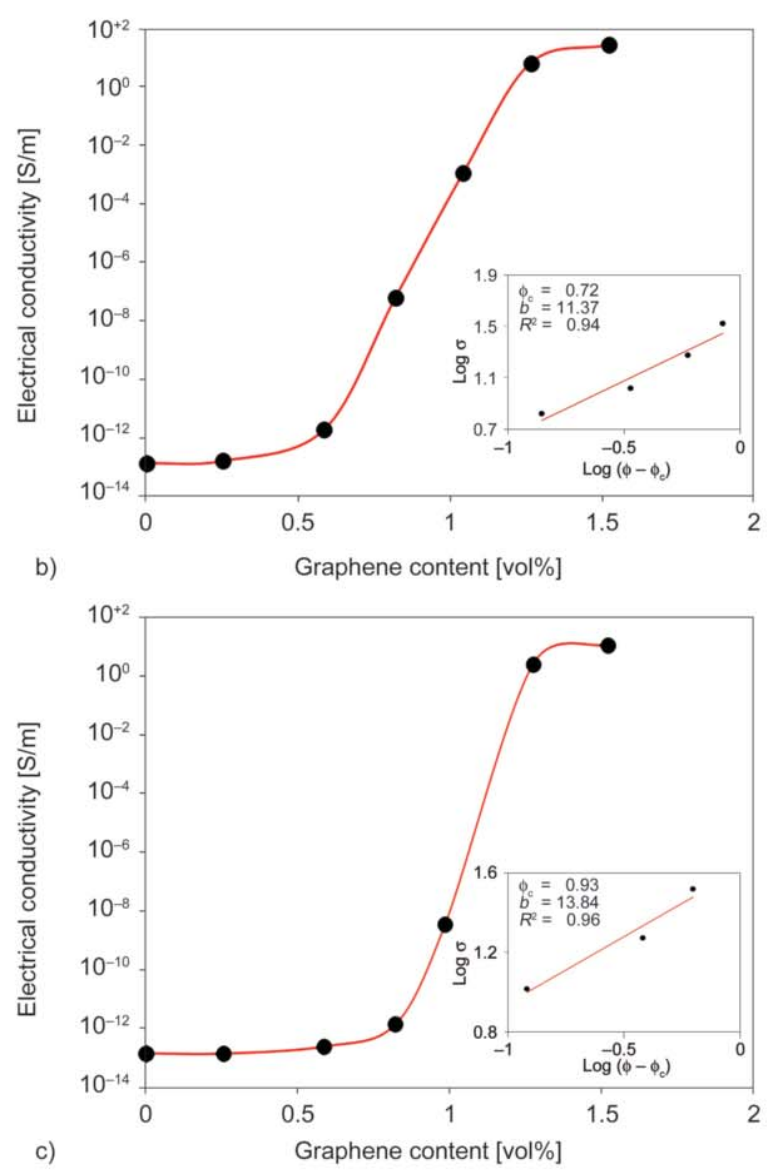

Figure 11. Electrical Conductivity of epoxy nanocomposites as a function of GNP loading for a) LVR b) MVR c) HVR. Inset demonstrated log-log plots of $\sigma$ against $\left(\phi-\phi_{\mathrm{c}}\right)$.

trend is known as the electrical percolation threshold. The point at which the electrical percolation threshold occurs was disparate for each category of composite specimens. This value can be determined from power law according to Equation (2) [41]:

$\sigma=\sigma_{0}\left(\phi-\phi_{c}\right)^{b}$

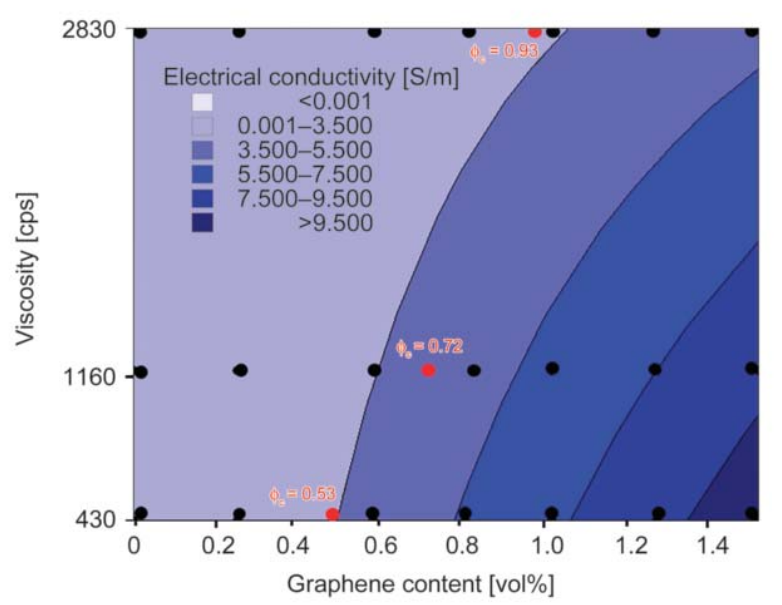

Figure 12. Contour plot showing the role of GNP content and viscosity variation in electrical conductivity of composites.

where $\sigma_{0}$ is GNPs conductivity, $\phi$ is the volume fraction of GNPs, $\phi_{\mathrm{c}}$ is the critical volume fraction at percolation threshold and ' $b$ ' is the scaling critical exponent used to determine the mechanism of GNPs network formation. It was shown, Figure 11a that a percolation threshold appeared for the samples manufactured from LVR at $0.53 \mathrm{vol} \%$, from MVR at $0.72 \mathrm{vol} \%$, and from HVR at $0.93 \mathrm{vol} \%$ (see also contour plot in Figure 12). Thus, the lowest GNPs content at which percolation threshold occurred was in LVR composites, while in MVR and HVR, much larger amounts of GNPs were needed to obtain a remarkably conductive composite. Furthermore, based on experimental data depicted in Figure 11, the double logarithmic graph of $\sigma$ versus $\left(\phi-\phi_{c}\right)$ and the fitted line along with $t$ values are presented in insets. As seen, $b$ values differ remarkably for LVR, MVR, and HVR composites. It should be mentioned that the extent of dispersion does play a pivotal role in determining $b$ values [38]. The smaller value of $b$ exemplifies more homogenous GNPs dispersion and thinner structure of GNPs in the epoxy matrix [38]. Thus, the reduction in $b$ values with a decrease of matrix viscosity, which is seen in the result of the power-law model, substantiates the better dispersion of GNPs in LVR. This is in total agreement with rheological and XRD results and those visualized by SEM, TEM, and optical microscopy images.

\subsection{Dynamic mechanical properties}

Dynamic mechanical properties of epoxy composites with different viscosities reinforced with $1 \mathrm{wt} \%$ 


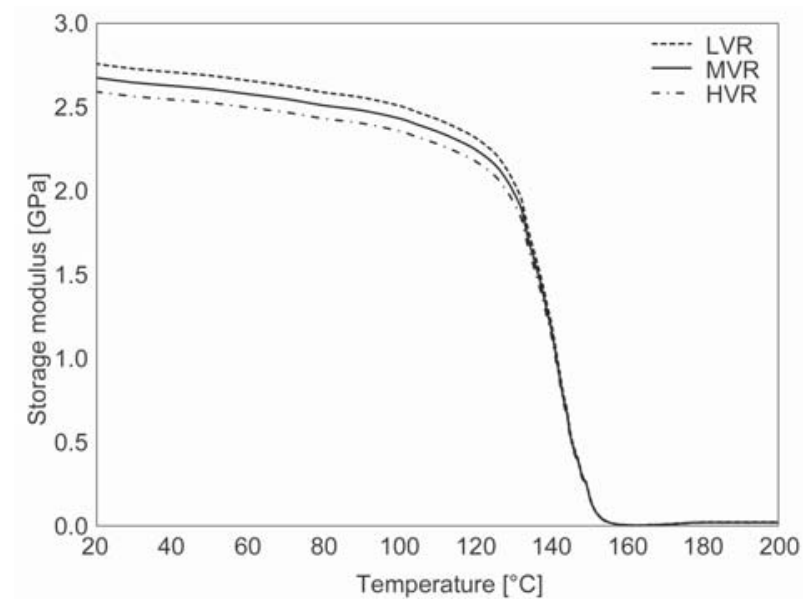

Figure 13. Storage moduli versus temperature for composites reinforced with $1 \mathrm{wt} \%$ of GNPs.

of GNPs are illustrated in Figure 13. Generally, nanoparticles like GNPs are expected to enhance the storage modulus of epoxy because once they are incorporated into the polymer matrix, the interaction between polymer chains and nanosheets will increase. The more uniform dispersion of GNP will undoubtedly bring about a more significant enhancement in storage modulus. As seen, despite the fact that there is not a huge difference between storage modulus of different composites, one made from LVR still shows a slightly higher modulus compared to those made from MVR and HVR, which is a result of more uniform dispersion of GNPs and thus the restricted mobility of polymer chains.

\section{Conclusions}

Among the various factors affecting the properties of graphene nanocomposites, the effect of matrix viscosity on the dispersion uniformity of graphene nano-platelets (GNPs) has been least studied. This study presented the results obtained by examination of the GNP dispersion within the epoxy matrix of various viscosities using morphological analysis and electrical percolation threshold theory. The following conclusions can be drawn:

1. The lowest intensity of graphitic peaks, at a fixed GNPs content, was found in reinforced composites based on LVR, indicating better intercalation of nanosheets compared to MVR and HVR.

2. SEM images demonstrated that at a higher resin viscosity, more agglomerations existed since much more nanosheets stacked to each other and formed thicker clusters.
3. The quantitative analysis conducted by TEM and optical microscopy also confirmed that agglomerations formed in LVR, compared to MVR and HVR, compromised of a fewer number of nanosheets.

4. The incorporation of GNPs enhanced rheological and electrical properties, while percolation thresholds were found to be lower when composites were made from LVR, substantiating better GNP dispersion.

This study not only investigated the effect of GNP dispersion in resin with different viscosities, but also concluded the composites made from low-viscosity resin, in spite of probable re-stacking of GNPs, have a more uniform dispersion than composites made form medium-viscosity and high-viscosity resins. It is envisaged that the findings from this study can provide a guideline for selecting proper matrix viscosity to maximize the performance of the GNP/ epoxy nanocomposites.

\section{References}

[1] Oh H., Kim K., Ryu S., Kim J.: Enhancement of thermal conductivity of polymethyl methacrylate-coated graphene/epoxy composites using admicellar polymerization with different ionic surfactants. Composites Part A: Applied Science and Manufacturing, 116, 206-215 (2019). https://doi.org/10.1016/j.compositesa.2018.10.035

[2] Hou L., Gao J., Ruan H., Xu X., Lu S.: Mechanical and thermal properties of hyperbranched poly( $\varepsilon$-caprolactone) modified graphene/epoxy composites. Journal of Polymer Research, 27, 27-32 (2020). https://doi.org/10.1007/s10965-020-2008-x

[3] Yadav A., Kumar A., Singh P. K., Sharma K.: Glass transition temperature of functionalized graphene epoxy composites using molecular dynamics simulation. Integrated Ferroelectrics, 186, 106-114 (2018).

https://doi.org/10.1080/10584587.2017.1370331

[4] Kothmann M. H., Zeiler R., de Anda A. R., Brückner A., Altstädt V.: Fatigue crack propagation behaviour of epoxy resins modified with silica-nanoparticles. Polymer, 60, 157-163 (2015).

https://doi.org/10.1016/j.polymer.2015.01.036

[5] Zhou H., Wang H., Du X., Zhang Y., Zhou H., Yuan H., Liu H-Y., Mai Y-W.: Facile fabrication of large 3D graphene filler modified epoxy composites with improved thermal conduction and tribological performance. Carbon, 139, 1168-1177 (2018). https://doi.org/10.1016/j.carbon.2018.07.059

[6] Park M-S., Lee S., Lee Y-S.: Mechanical properties of epoxy composites reinforced with ammonia-treated graphene oxides. Carbon Letters, 21, 1-7 (2017). https://doi.org/10.5714/c1.2017.21.001 
[7] Zhang B., Wang J., Tan H., Su X., Huo S., Yang S., Chen W., Wang J.: Synthesis of Fe@Ni nanoparticlesmodified graphene/epoxy composites with enhanced microwave absorption performance. Journal of Materials Science: Materials in Electronics, 29, 3348-3357 (2018).

https://doi.org/10.1007/s10854-017-8270-y

[8] Zheng W., Chen W. G., Zhao Q., Ren S. X., Fu Y. Q.: Interfacial structures and mechanisms for strengthening and enhanced conductivity of graphene/epoxy nanocomposites. Polymer, 163, 171-177 (2019). https://doi.org/10.1016/j.polymer.2018.12.055

[9] Li Y., Zhang H., Crespo H., Porwal M., Picot H., Santagiuliana O., Huang G., Barbieri Z., Pugno E., Peijs T. N. M., Bilotti E.: In situ exfoliation of graphene in epoxy resins: A facile strategy to efficient and large scale graphene nanocomposites. ACS Applied Materials and Interfaces, 8, 24112-24122 (2016). https://doi.org/10.1021/acsami.6b07492

[10] Wu S., Ladani R. B., Zhang J., Bafekrpour E., Ghorbani K., Mouritz A. P., Kinloch A. J., Wang C. H.: Aligning multilayer graphene flakes with an external electric field to improve multifunctional properties of epoxy nanocomposites. Carbon, 94, 607-618 (2015). https://doi.org/10.1016/j.carbon.2015.07.026

[11] Ahmadi-Moghadam B., Taheri F.: Effect of processing parameters on the structure and multi-functional performance of epoxy/GNP-nanocomposites. Journal of Materials Science, 49, 6180-6190 (2014). https://doi.org/10.1007/s10853-014-8332-y

[12] Chhetri S., Adak N. C., Samanta P., Murmu N. C., Hui D., Kuila T., Lee J. H.: Investigation of the mechanical and thermal properties of L-glutathione modified graphene/epoxy composites. Composites Part B: Engineering, 143, 105-112 (2018).

https://doi.org/10.1016/j.compositesb.2018.02.004

[13] Mousavi A., Roghani-Mamaqani H., Salami-Kalajahi M., Shahi S., Abdollahi A.: Modification of graphene with silica nanoparticles for use in hybrid network formation from epoxy, novolac, and epoxidized novolac resins by sol-gel method: Investigation of thermal properties. Express Polymer Letters, 12, 187-202 (2018). https://doi.org/10.3144/expresspolymlett.2018.18

[14] Oh H., Kim Y., Kim J.: Co-curable poly(glycidyl methacrylate)-grafted graphene/epoxy composite for thermal conductivity enhancement. Polymer, 183, 121834/1-121834/9 (2019).

https://doi.org/10.1016/j.polymer.2019.121834

[15] Silva A. A., Stein R., Campos D. D. O., Indrusiak T., Soares B. G., Barra G. M. D. O.: Conducting materials based on epoxy/graphene nanoplatelet composites with microwave absorbing properties: Effect of the processing conditions and ionic liquid. Frontiers in Materials, 6, 1562019/1-1562019/9 (2019).

https://doi.org/10.3389/fmats.2019.00156
[16] Dong Y., Bhattacharyya D.: Effects of clay type, clay/ compatibiliser content and matrix viscosity on the mechanical properties of polypropylene/organoclay nanocomposites. Composites Part A: Applied Science and Manufacturing, 39, 1177-1191 (2008).

https://doi.org/10.1016/j.compositesa.2008.03.006

[17] Ha H., Kim S. C., Ha K.: Effect of molecular weight of polymer matrix on the dispersion of MWNTs in HDPE/ MWNT and PC/MWNT composites. Macromolecular Research, 18, 512-518 (2010). https://doi.org/10.1007/s13233-010-0510-4

[18] Hermant M. C., Smeets N. M., van Hal R. C., Meuldijk J., Heuts H. P., Klumperman B., van Herk A. M., Koning C. E.: Influence of the molecular weight distribution on the percolation threshold of carbon nanotube - polystyrene composites. e-Polymers, 9, 22/1-22/13 (2009). https://doi.org/10.1515/epoly.2009.9.1.248

[19] Ivanov E., Velichkova H., Kotsilkova R., Bistarelli S., Cataldo A., Micciulla F., Bellucci S.: Rheological behavior of graphene/epoxy nanodispersions. Applied Rheology, 27, 24469/1-24469/9 (2017).

https://doi.org/10.3933/applrheol-27-24469

[20] Galindo-Rosales F. J., Moldenaers P., Vermant J.: Assessment of the dispersion quality in polymer nanocomposites by rheological methods. Macromolecular Materials and Engineering, 296, 331-340 (2011).

https://doi.org/10.1002/mame.201000345

[21] Kotsilkova R., Ivanov E., Bychanok D., Paddubskaya A., Demidenko M., Macutkevic J., Maksimenko S., Kuzhir P.: Effects of sonochemical modification of carbon nanotubes on electrical and electromagnetic shielding properties of epoxy composites. Composites Science and Technology, 106, 85-92 (2015).

https://doi.org/10.1016/j.compscitech.2014.11.004

[22] Hashjin R. R., Ranjbar Z., Yari H.: Modeling of electrical conductive graphene filled epoxy coatings. Progress in Organic Coatings, 125, 411-419 (2018). https://doi.org/10.1016/j.porgcoat.2018.09.030

[23] Li A., Zhang C., Zhang Y-F.: Graphene nanosheetsfilled epoxy composites prepared by a fast dispersion method. Journal of Applied Polymer Science, 134, 45152/1-45152/7 (2017).

https://doi.org/10.1002/app.45152

[24] Li Y., Zhang Y., Porwal H., Huang Z., Bilotti E., Peijs T.: Mechanical, electrical and thermal properties of $i n-$ situ exfoliated graphene/epoxy nanocomposites. Composites Part A: Applied Science and Manufacturing, 95, 229-236 (2017).

https://doi.org/10.1016/j.compositesa.2017.01.007

[25] Wang Y., Shan J. W., Weng G. J.: Percolation threshold and electrical conductivity of graphene-based nanocomposites with filler agglomeration and interfacial tunneling. Journal of Applied Physics, 118, 065101/1065101/10 (2015).

https://doi.org/10.1063/1.4928293 
[26] Zhang H-B., Zheng W-G., Yan Q., Yang Y., Wang J-W., Lu Z-H., Ji G-Y., Yu Z-Z.: Electrically conductive polyethylene terephthalate/graphene nanocomposites prepared by melt compounding. Polymer, 51, 1191-1196 (2010). https://doi.org/10.1016/j.polymer.2010.01.027

[27] Kuilla T., Bhadra S., Yao D., Kim N. H., Bose S., Lee J. H.: Recent advances in graphene based polymer composites. Progress in Polymer Science, 35, 1350-1375 (2010). https://doi.org/10.1016/j.progpolymsci.2010.07.005

[28] Zaman I., Kuan H-C., Meng Q., Michelmore A., Kawashima N., Pitt T., Zhang L., Gouda S., Luong L., Ma J.: A facile approach to chemically modified graphene and its polymer nanocomposites. Advanced Functional Materials, 22, 2735-2743 (2012).

https://doi.org/10.1002/adfm.201103041

[29] Clark S. M., Jeon K-J., Chen J-Y., Yoo C-S.: Few-layer graphene under high pressure: Raman and $\mathrm{X}$-ray diffraction studies. Solid State Communications, 154, 1518 (2013). https://doi.org/10.1016/j.ssc.2012.10.002

[30] Prolongo S. G., Jiménez-Suárez A., Moriche R., Ureña A.: Graphene nanoplatelets thickness and lateral size influence on the morphology and behavior of epoxy composites. European Polymer Journal, 53, 292-301 (2014).

https://doi.org/10.1016/j.eurpolymj.2014.01.019

[31] Chhetri S., Samanta P., Murmu N. C., Srivastava S. K., Kuila T.: Effect of dodecyal amine functionalized graphene on the mechanical and thermal properties of epoxy-based composites. Polymer Engineering and Science, 56, 1221-1228 (2016).

https://doi.org/10.1002/pen.24355

[32] Haghnegahdar M., Naderi G., Ghoreishy M. H. R.: Microstructure and mechanical properties of nanocomposite based on polypropylene/ethylene propylene diene monomer/graphene. International Polymer Processing, 32, 72-83 (2017).

https://doi.org/10.3139/217.3286

[33] Alipour A., Naderi G., Bakhshandeh G. R., Vali H., Shokoohi S.: Elastomer nanocomposites based on NR/ EPDM/organoclay: Morphology and properties. International Polymer Processing, 26, 48-55 (2011). https://doi.org/10.3139/217.2381
[34] Adrar S., Habi A., Ajji A., Grohens Y.: Combined effect of epoxy functionalized graphene and organomontmorillonites on the morphology, rheological and thermal properties of poly (butylenes adipate-co-terephtalate) with or without a compatibilizer. Applied Clay Science, 146, 306-315 (2017). https://doi.org/10.1016/j.clay.2017.06.009

[35] Martin-Gallego M., Bernal M., Hernandez M., Verdejo R., Lopez-Manchado A.: Comparison of filler percolation and mechanical properties in graphene and carbon nanotubes filled epoxy nanocomposites. European Polymer Journal, 49, 1347-1353 (2013).

https://doi.org/10.1016/j.eurpolymj.2013.02.033

[36] Nan C-W., Shen Y., Ma J.: Physical properties of composites near percolation. Annual Review of Materials Research, 40, 131-151 (2010). https://doi.org/10.1146/annurev-matsci-070909-104529

[37] Choi H-J., Kim M. S., Ahn D., Yeo S. Y., Lee S.: Electrical percolation threshold of carbon black in a polymer matrix and its application to antistatic fibre. Scientific Reports, 9, 1-12 (2019). https://doi.org/10.1038/s41598-019-42495-1

[38] Haghnegahdar M., Naderi G., Ghoreishy M. H. R.: Electrical and thermal properties of a thermoplastic elastomer nanocomposite based on polypropylene/ethylene propylene diene monomer/graphene. Soft Materials, 15, 82-94 (2017). https://doi.org/10.1080/1539445x.2016.1268622

[39] Ghaleb Z. A., Mariatti M., Ariff Z. M.: Properties of graphene nanopowder and multi-walled carbon nanotube-filled epoxy thin-film nanocomposites for electronic applications: The effect of sonication time and filler loading. Composites Part A: Applied Science and Manufacturing, 58, 77-83 (2014).

https://doi.org/10.1016/j.compositesa.2013.12.002

[40] Alig I., Lellinger D., Dudkin S. M., Pötschke P.: Conductivity spectroscopy on melt processed polypropylene-multiwalled carbon nanotube composites: Recovery after shear and crystallization. Polymer, 48, 10201029 (2007). https://doi.org/10.1016/j.polymer.2006.12.035

[41] Lu L., Xing D., Xie Y., Teh K. S., Zhang B., Chen S., Tang Y.: Electrical conductivity investigation of a nonwoven fabric composed of carbon fibers and polypropylene/polyethylene core/sheath bicomponent fibers. Materials and Design, 112, 383-391 (2016). https://doi.org/10.1016/j.matdes.2016.09.096 